Plant $\mathcal{O}^{\circ}$ Cell Physiol. 25(8): 1379-1388 (1984)

JSPP (C) 1984

\title{
Measurement of Stomatal Aperture by Digital Image Processing
}

\author{
Kenji Omasa ${ }^{1}$ and Morio Onoe ${ }^{2}$ \\ 1 Division of Engineering, The National Institute for Environmental Studies, Yatabe, Ibaraki 305, Japan \\ 2 Institule of Industrial Science, Universily of Tokyo, Roppongi, Tokyo 106, Japan
}

\begin{abstract}
We developed a new digital image processing technique for exactly measuring the degree of stomatal opening, that is, the ratio of the width to the maximum length of a stomatal pore, and the pore area. We applied this technique to evaluate responses to $\mathrm{SO}_{2}$ of neighboring stomata in a small region of an intact attached leaf, with the following results:

1) The pore region could be exactly extracted even when the original digital image was of poor quality. The standard errors in the evaluation of the pore area, the pore length, and the pore width were $10 \mu \mathrm{m}^{2}, 0.3 \mu \mathrm{m}$ and $0.3 \mu \mathrm{m}$, respectively.

2) A wide variety of responses to $\mathrm{SO}_{2}$ was found among neighboring stomata in a small region of an attached leaf. The differences were especially remarkable before water-soaking and wilting. When these began, $\mathrm{k}_{1}$ showed a local maximum value, and then all the stomata began to close. These results suggest that stomatal responses of intact growing plants to air pollutants should be examined from the standpoint of not only the average movement of many stomata but also the movement of each stoma and that the interrelationship among movements of neighboring stomata should be investigated to clarify the mechanism of stomatal responses to air pollutants.
\end{abstract}

Key words: Air pollutant - Digital image processing - Helianthus annuus Stomatal aperture - Stomatal response.

Digital image processing has rapidly progressed with the growth of computer technology and is being widely utilized in the fields of television, remote sensing, and medicine (Hounsfield 1973, Rosenfeld and Kak 1976, Castleman 1979, Onoe et al. 1981). This technique recently began to be applied in the fields of physiological ecology and plant physiology (Hashimoto and Niwa 1978, Omasa et al. 1981a, b, c, 1983a, Hashimoto et al. 1983, Mineyuki et al. 1983, Onoe et al. 1983, Telewski et al. 1983, Mineyuki et al. 1984, Omasa and Aiga 1985).

The stomatal aperture is generally measured with a ruler after the stomatal photograph has been taken using a scanning electron microscope and a light microscope. Since this method involves visual observation to determine the edge of a stomatal pore, the result depends upon the experience and knowledge of the person and inevitably includes some element of subjectivity. Therefore, an objective instrumental technique needed to be developed by digital image processing.

When the brightness of the stomatal pore differs remarkably from those of the guard cell and the epidermal cell, the pore can be easily extracted from the surrounding cells by simple thresh-

\footnotetext{
Abbreviations: $l_{a}$, width of a stomatal pore; $l_{b}$, length of a stomatal pore; $l_{b \max }, l_{b}$ of an open stoma, i.e., maximum value of $l_{b} ; k_{1}$, degree of stomatal opening expressed by $l_{a} / l_{b \max } ; A_{r}$, area of a stomatal pore; SIT, silicon intensifier target; FSS, flying spot scanner; RH, relative humidity; ppm (v/v), parts per million in volume
} units. 
olding of the original image, which is a digital image processing technique. Hashimoto et al. (1983) recently evaluated the pore area of stomata observed with a scanning electron microscope by this method. However, since many stomatal images, especially those observed with a light microscope, do not satisfy the above condition and the edge of the stomatal pore is not clear, the simple thresholding cannot be used for pore extraction. Also, there has been no report on the objective evaluation of pore width and pore length, which are used as the common indicator of stomatal aperture.

We, therefore, developed a new digital image processing technique for exactly measuring the degree of stomatal opening, that is, the ratio of the width to the maximum length of a stomatal pore, and the pore area as indicators of stomatal aperture. We also applied this technique to evaluate the responses to $\mathrm{SO}_{2}$ of neighboring stomata in a small region of an intact attached leaf.

\section{Materials and Methods}

Plant materials-Sunflower (Helianthus annuus L cv. Russian Mammoth) plants were grown in an environment-control greenhouse (Aiga et al. 1982) at $25 / 20^{\circ} \mathrm{C}$ day $/$ night temperature and $70 \%$ RH under natural light for 4 to 6 weeks after being sown in pots. The pots were filled with a $4: 2: 4: 1(\mathrm{v} / \mathrm{v})$ mixture of vermiculite, perlite, peat moss, and fine gravel, which was moistened with nutrient solution. The plants were irrigated daily. After the test plants had been moved to an environment-control chamber designed for studies of air pollution effects on plants (Aiga et al. 1982) and acclimatized to the new conditions, mature leaves of the intact plants were used in the experiments.

Observation of stomatal responses to air pollutants-Stomatal responses of intact growing plants to $\mathrm{SO}_{2}$ and $\mathrm{O}_{3}$ were continuously observed using a remote-control light microscope system (Omasa et al. 1983b). A light microscope with a wide working distance (about $13 \mathrm{~mm}$ ) at high magnification (a $50 \times$ objective, $1.5 \times$ and $2 \times$ amplifiers and a TV adapter lens) and an SIT camera head with high sensitivity were set in the chamber. An attached leaf was fastened to a movable microscope stage and illuminated until its stomatal apertures attained a steady state, after which the leaf was treated with air pollutants. During the experiments, the microscope image was projected onto a TV monitor outside the chamber, giving about $800 \times$ to $1,600 \times$ magnification with high resolution and little distortion. The images were recorded photographically on blackand-white negative roll film for later study. Camera sensitivity, microscope focus, and movement of the microscope stage were adjusted by remote controllers outside the chamber. Air temperature and relative humidity in the chamber and around the leaf were maintained at $25.0^{\circ} \mathrm{C}$ and $60 \%$. The leaf was illuminated with tungsten lamps at about $600 \mu \mathrm{E} \cdot \mathrm{m}^{-2} \cdot \mathrm{s}^{-1}$ with the light passing through heat-absorbing filters.

Digital image processing system-The stomatal image photographed on the negative film was converted with an FSS into a digital image $\left(256^{\mathrm{H}} \times 256^{\mathrm{v}}, 256\right.$ gray levels), which was analyzed by a computer system with a monochromatic TV monitor for image display.

Principle and procedure of image processing-Fig. I shows the flow diagram of digital image processing for evaluating the pore width, the pore length and the pore area as indicators of stomatal aperture.

The original digital image converted by the FSS involved scanning lines of the TV monitor. The brightness of the stomatal pore in the image did not differ sufficiently to allow thresholding from those of the guard cell and the epidermal cell, and the edge of the pore was not clear. Therefore, filtering by discrete Fourier transform and unsharp masking were used to remove the $\mathrm{TV}$ scanning lines and to enhance the image as a first step of the image processing. 


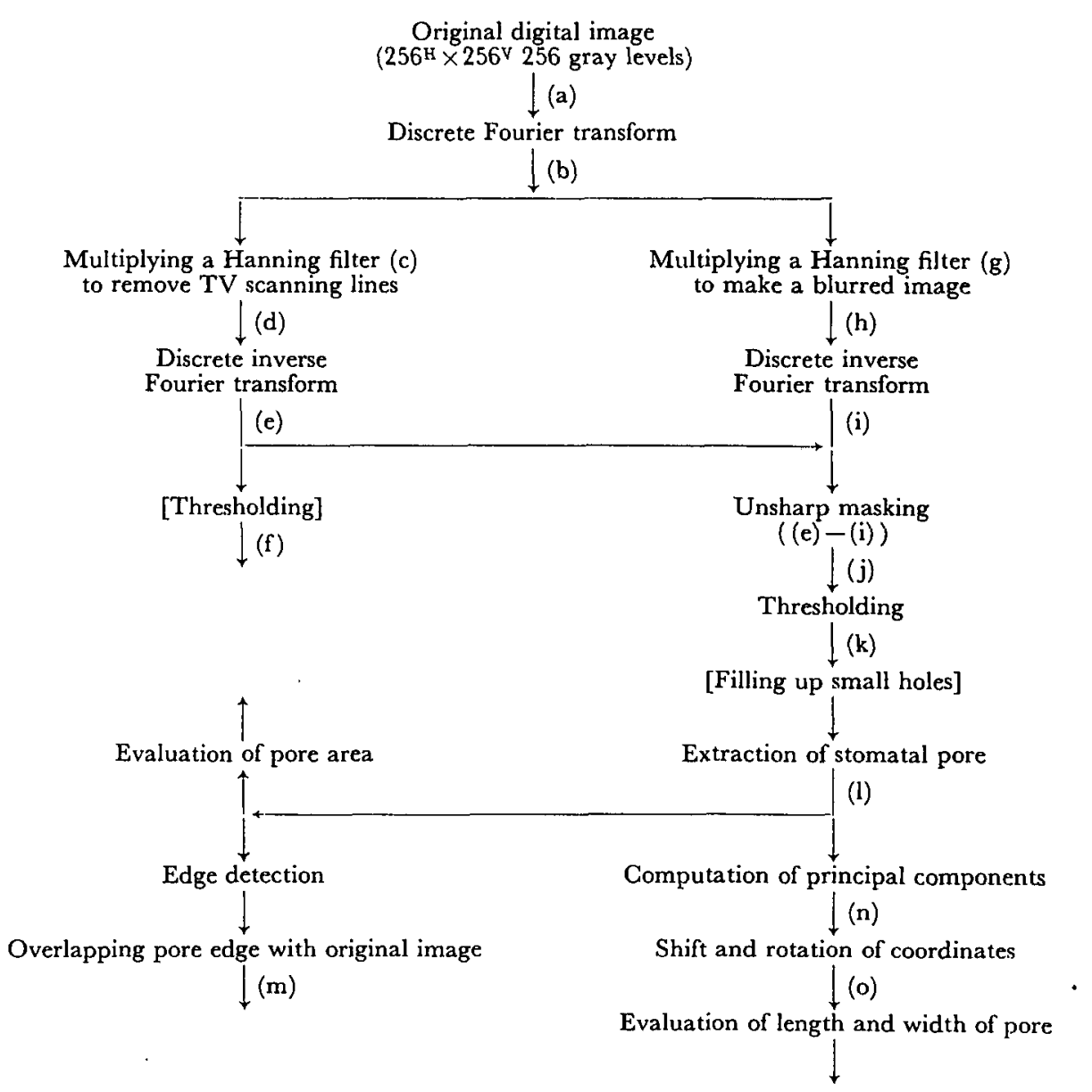

Fig. 1 Flow diagram of digital image processing for evaluating width, length and area of a stomatal pore.

With $f(x, y)$ as the gray level at the pixel $(x, y=0,1,2, \cdots, N-1)$ in the original digital image, the two-dimensional discrete Fourier transform $F(u-N / 2, v-N / 2)$ of $f(x, y)$, where the origin after the transform was moved to the center of frequency square, was given by

$$
\mathrm{F}(\mathrm{u}-\mathrm{N} / 2, \mathrm{v}-\mathrm{N} / 2)=\frac{1}{\mathrm{~N}} \sum_{\mathrm{x}=0}^{\mathrm{N}-1} \sum_{\mathrm{y}=0}^{N-1}(-1)^{\mathrm{x}+\mathrm{y}} \mathrm{f}(\mathrm{x}, \mathrm{y}) \exp [-\mathrm{j} 2 \pi(\mathrm{ux}+\mathrm{vy}) / \mathrm{N}]
$$

for $u, v=0,1,2, \cdots, N-1$.

After multiplying $\mathrm{F}(\mathrm{u}-\mathrm{N} / 2, \mathrm{v}-\mathrm{N} / 2)$ by the Hanning filter $\mathrm{H}\left(\mathrm{u}-\mathrm{N} / 2, \mathrm{v}-\mathrm{N} / 2, \mathrm{f}_{\mathrm{c}}\right)$ to remove the TV scanning lines or to obtain a blurred image for the unsharp masking, each inverse Fourier transform $g\left(x^{\prime}, y^{\prime}, f_{c}\right)$ could be expressed by

$$
\begin{array}{r}
g\left(x^{\prime}, y^{\prime}, f_{c}\right)=\frac{1}{N}(-1)^{x+y} \sum_{u=0}^{N-1} \sum_{v=0}^{N-1}(-1)^{u+v} H\left(u-N / 2, v-N / 2, f_{c}\right) \\
\times F(u-N / 2, v-N / 2) \exp [j 2 \pi(u x+v y) / N]
\end{array}
$$

for $x^{\prime}=x-N / 2$ and $y^{\prime}=y-N / 2$, where 


$$
H\left(u-N / 2, v-N / 2, f_{c}\right)= \begin{cases}0 & \text { if } f_{u v} \geq f_{c} \\ \frac{1}{2}\left[1+\cos \left(\pi f_{u v} / f_{c}\right)\right] & \text { if } f_{u v}<f_{c}\end{cases}
$$

and

$$
f_{u v}=\left[(u-N / 2)^{2}+(v-N / 2)^{2}\right]^{1 / 2}
$$

The parameter $f_{c}$ of the Hanning filter was determined according to the above purpose. The unsharp masking, in which the blurred image $g\left(x^{\prime}, y^{\prime}, f_{c 2}\right)$ ( (i) in Fig. 1) was subtracted from image $g\left(x^{\prime}, y^{\prime}, f_{c 1}\right)$ (e) after removal of the TV scanning lines, had the effect of increasing the average ramp steepness and of increasing the contrast just at the pore edge. The unsharp masked image $g_{u}\left(x^{\prime}, y^{\prime}\right)$ was given by

$$
g_{\mathfrak{u}}\left(x^{\prime}, y^{\prime}\right)=g\left(x^{\prime}, y^{\prime}, f_{c 1}\right)-g\left(x^{\prime}, y^{\prime}, f_{c 2}\right)
$$

The pore region of appointed stoma could be extracted from the neighboring cells by thresholding $g_{u}\left(x^{\prime}, y^{\prime}\right)$. The result could be expressed as the two-valued image $g_{\Upsilon}\left(x^{\prime}, y^{\prime}\right)$.

$$
\mathrm{g}_{\mathrm{T}}\left(\mathrm{x}^{\prime}, \mathrm{y}^{\prime}\right)= \begin{cases}1 & \text { if } \mathrm{g}_{\mathrm{u}}\left(\mathrm{x}^{\prime}, \mathrm{y}^{\prime}\right) \geq \mathrm{T} \text { at appointed stoma } \\ 0 & \text { otherwise }\end{cases}
$$

where $\mathrm{T}$ is a threshold. The threshold was determined to be about zero in the gray level of the unsharp masked image and to give the maximum area in the pore region extracted elliptically. When there were small holes in the threshold region due to poor quality of the original image (although this was unusual), the holes were completely filled up.

The area $A_{r}$ of the stomatal pore was obtained by counting pixels in the extracted region.

$$
A_{r}=k^{2} \mathrm{~A}
$$

where

$$
A=\sum_{x^{\prime}=-N / 2}^{N / 2-1} \sum_{y^{\prime}=-N / 2}^{N / 2-1} g_{T}\left(x^{\prime}, y^{\prime}\right)
$$

and $\mathrm{k}$ is a coefficient for correcting the magnification.

The pore width $l_{a}$ and the pore length $l_{b}$ were evaluated from frequency distributions to two

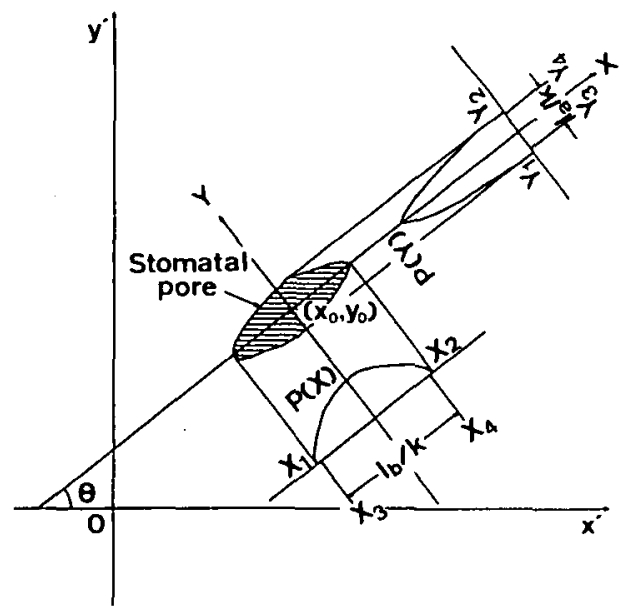

Fig. 2 Conception for evaluating width and length of a stomatal pore. 
rectangular principal components of the extracted region (Fig. 2). The principal components $\mathrm{X}, \mathrm{Y}$ were defined by

$$
\mathrm{X}=\left(\mathrm{x}^{\prime}-\mathrm{x}_{0}\right) \cos \theta+\left(\mathrm{y}^{\prime}-\mathrm{y}_{0}\right) \sin \theta
$$

and

$$
\mathrm{Y}=-\left(\mathrm{x}^{\prime}-\mathrm{x}_{0}\right) \sin \theta+\left(\mathrm{y}^{\prime}-\mathrm{y}_{0}\right) \cos \theta
$$

where

$$
\begin{aligned}
& x_{0}=\frac{1}{A} \sum_{x^{\prime}=-N / 2}^{N / 2-1} \sum_{y^{\prime}=-N / 2}^{N / 2-1} x^{\prime} g_{T}\left(x^{\prime}, y^{\prime}\right) \\
& y_{0}=\frac{1}{A} \sum_{x^{\prime}=-N / 2}^{N / 2-1} \sum_{y^{\prime}=-N / 2}^{N / 2-1} y^{\prime} g_{T}\left(x^{\prime}, y^{\prime}\right) \\
& \theta=\frac{1}{2} \tan -1\left[2 S_{x y} /\left(S_{x x}-S_{y y}\right)\right] \\
& S_{x x}=\sum_{x^{\prime}=-N / 2}^{N / 2-1} \sum_{y^{\prime}=-N / 2}^{N / 2-1}\left(x^{\prime}-x_{0}\right)^{2} g_{T}\left(x^{\prime}, y^{\prime}\right) \\
& S_{y y}=\sum_{x^{\prime}=-N / 2}^{N / 2-1} \sum_{y^{\prime}=-N / 2}^{N / 2-1}\left(y^{\prime}-y_{0}\right)^{2} g_{T}\left(x^{\prime}, y^{\prime}\right)
\end{aligned}
$$

and

$$
S_{x y}=\sum_{x^{\prime}=-N / 2}^{N / 2-1} \sum_{y^{\prime}=-N / 2}^{N / 2-1}\left(x^{\prime}-x_{0}\right)\left(y^{\prime}-y_{0}\right) g_{T}\left(x^{\prime}, y^{\prime}\right)
$$

With $P(X)$ and $P(Y)$ as the frequency distributions to principal components $X, Y$, they were evaluated by computer after the shift and rotation of coordinates from $x^{\prime}$ and $y^{\prime}$ to $X$ and $Y$, and then $l_{a}$ and $l_{b}$ were determined from

$$
\begin{aligned}
& l_{a}=k\left(Y_{4}-Y_{3}\right) \\
& l_{b}=k\left(X_{4}-X_{3}\right)
\end{aligned}
$$

where $X_{1}$ to $X_{4}$ and $Y_{1}$ to $Y_{4}$ were defined by

$$
\begin{array}{ll}
P\left(X_{1}\right)=P\left(X_{2}\right)=0 & X_{2}>X_{1} \\
P\left(Y_{1}\right)=P\left(Y_{2}\right)=0 & Y_{2}>Y_{1} \\
\sum_{X=X_{1}}^{X_{3}} P(X)=\sum_{X=X_{4}}^{X_{2}} P(X)=0.005 A & X_{4}>X_{3}
\end{array}
$$

and

$$
\sum_{Y=Y_{1}}^{Y_{3}} \mathrm{P}(\mathrm{Y})=\sum_{\mathrm{Y}=\mathrm{Y}_{4}}^{\mathrm{Y}_{2}} \mathrm{P}(\mathrm{Y})=0.005 \mathrm{~A} \quad \mathrm{Y}_{4}>\mathrm{Y}_{3}
$$

The degree of the stomatal opening $k_{1}$ was expressed by the ratio $l_{a} / l_{b \max }$, where $l_{b \max }$ was the length $l_{b}$ of the stomatal pore of an opened stoma, that is, the maximum value of $l_{b}$. The edge of a stomatal pore could be detected from $\mathrm{g}_{\mathrm{T}}\left(\mathrm{x}^{\prime}, \mathrm{y}^{\prime}\right)$ by a simple difference operator.

\section{Results and Discussion}

Fig. 3 shows the sequence of the digital image processing for evaluating the stomatal aperture according to the flow diagram in Fig. 1. The original digital image (a) involved TV 

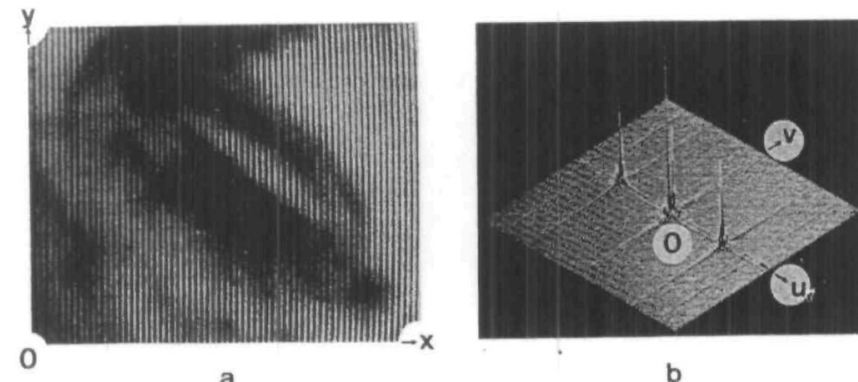

b

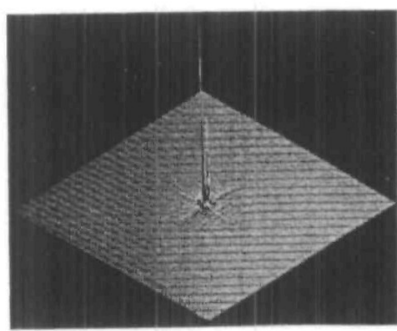

d

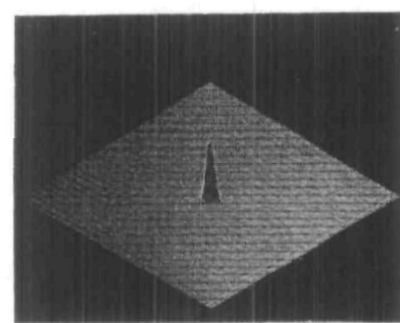

g

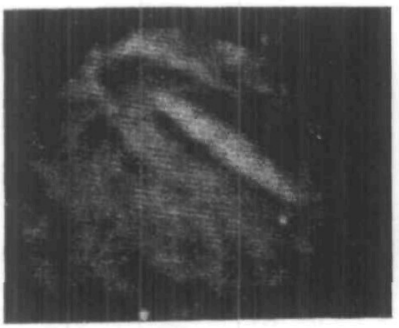

j

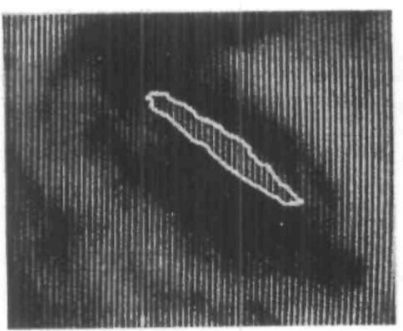

m

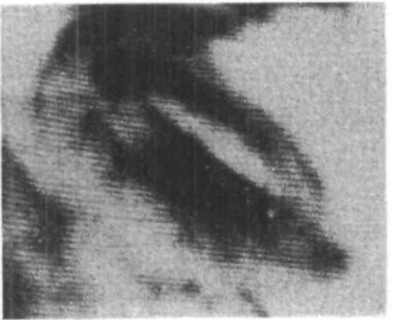

e

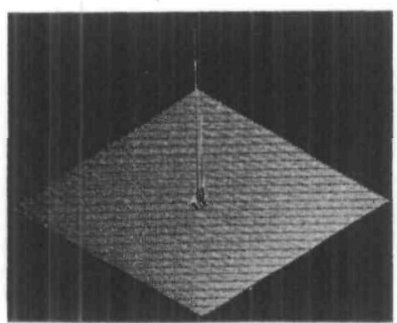

h

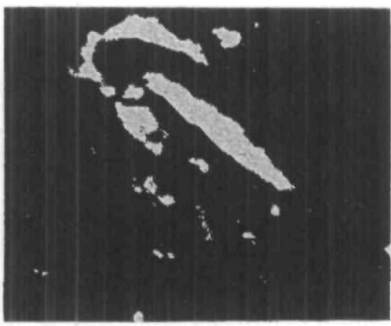

k

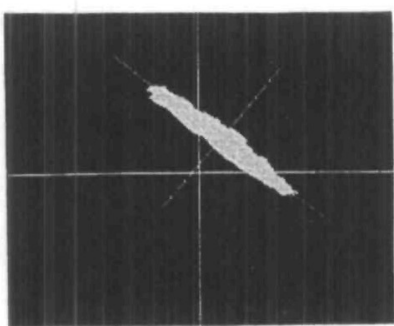

n

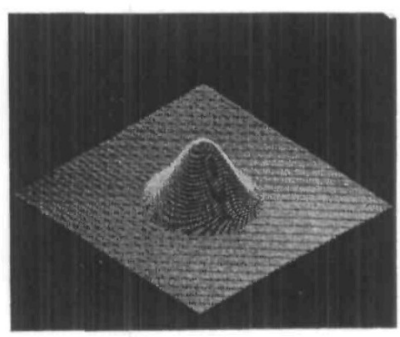

c

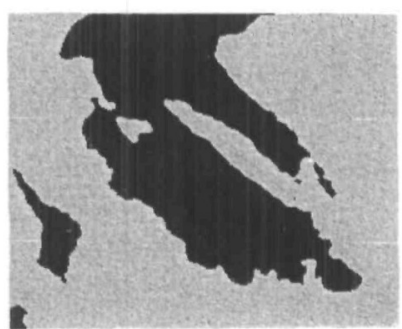

f
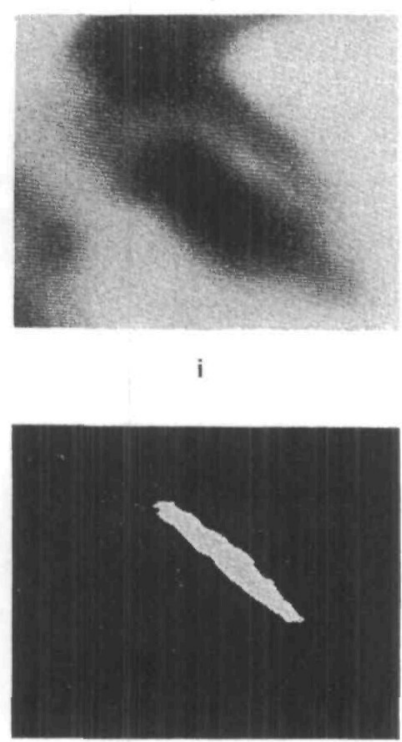

I

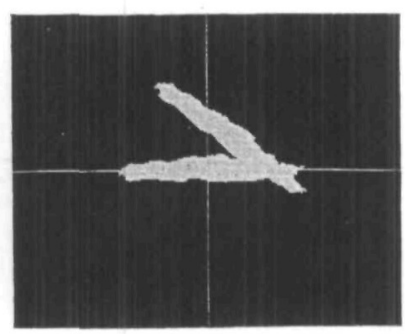

o 
Table 1 Accuracy in the evaluation of area, length, and width of a stomatal pore

\begin{tabular}{llll}
\hline & Area & Length & Width \\
\hline Mean value & $433 \mu \mathrm{m}^{2}$ & $34.1 \mu \mathrm{m}$ & $16.4 \mu \mathrm{m}$ \\
Standard error & 10 & 0.3 & 0.3 \\
\hline
\end{tabular}

scanning lines of vertical black-and-white stripes. Being clear and regular, the lines appeared as specific frequency components with sharp peaks at $u \simeq \pm 68$ in the Fourier spectrum (b) $|\mathrm{F}(\mathrm{u}-\mathrm{N} / 2, \mathrm{v}-\mathrm{N} / 2)|$ obtained from the magnitude of each of the transform terms. These components differed remarkably from low-frequency components with the information for the stomatal form. Therefore, the TV scanning lines were easily removed by a Hanning filter of $\mathrm{f}_{\mathrm{c}}=60$ (c), which was a low pass filter with the restraint function of frequency extension and leakage. The Fourier spectrum after the filtering and its inverse transform image are shown in (d) and (e), respectively. Since the brightness of the stomatal pore did not differ from that of the guard cell or the epidermal cell, the pore region could not be extracted by the simple thresholding (f). Thus, the unsharp masking was used for image sharpening. The blurred image (i) for the unsharp masking was obtained by the inverse transform of a Fourier spectrum (h) after multiplication with a Hanning filter of $f_{c}=10(\mathrm{~g})$. The unsharp masked image $(\mathrm{j})$ increased in contrast at the pore edge and in differences of brightness between the pore and its neighboring cells. Therefore, the pore region of the appointed stoma could be easily extracted from the neighboring cells after the thresholding; (k) was a two-valued image after the thresholding and (l) was a pore region extracted from the image $(\mathrm{k})$. From image $(\mathrm{m})$ obtained by overlapping the pore edge with the original image, we confirmed that the pore region had been exactly extracted. The pore area was computed from the extracted image (1). The pore width and the pore length were evaluated after the shift and rotation of coordinates to the principal components of the pore region; ( $n$ ) expressed principal components and $(0)$ the shift and rotation of the coordinates.

The quality of the original digital image depends upon the display image itself, the development of the film, the FSS conditions and other factors, and affects the accuracy of the stomatal aperture evaluation. Therefore, the accuracy was first examined using ten original images with the same stomatal aperture but with differences in quality and also using continuous images of

Fig. 4 Changes in $A_{r}$ and $k_{1}$ of a stoma during $\mathrm{O}_{3}$ exposure.

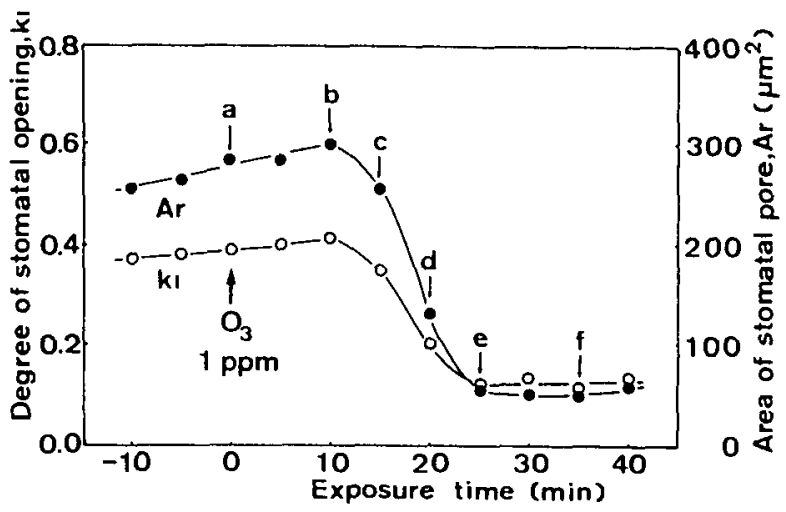

Fig. 3 Sequence of digital image processing for evaluating stomatal aperture according to the flow diagram of Fig. 1. (a) to (o) correspond to those in Fig. 1. The coordinates are shown in (a) for $(x, y)$ and (b) for $(u, v)$. 


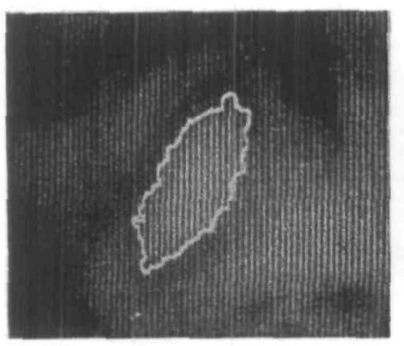

a

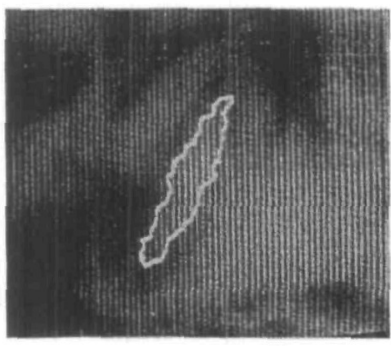

d

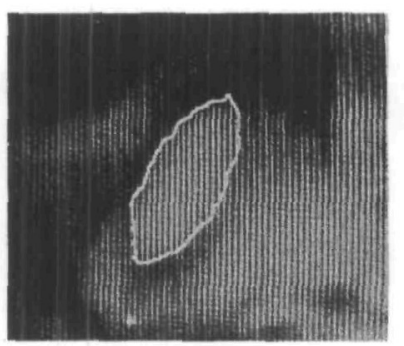

b

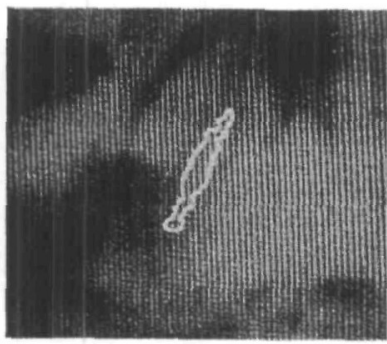

$\mathbf{e}$

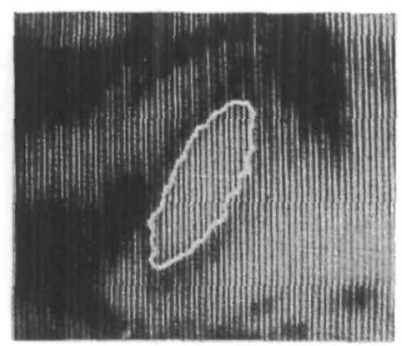

c

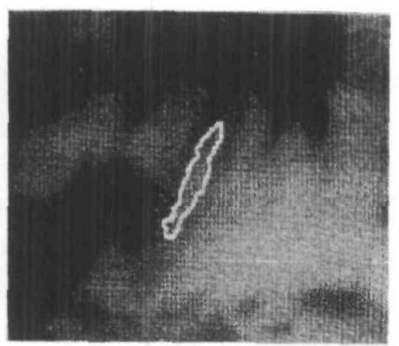

$\mathbf{f}$

Fig. 5 Original digital images overlapped with the pore edge at the time points (a to $f$ ) in Fig. 4.

different quality during $1 \mathrm{ppm}(\mathrm{v} / \mathrm{v}) \mathrm{O}_{3}$ exposure. Table 1 shows the standard errors in the evaluation of pore area, pore length, and pore width of the former ten stomatal images. The errors of the area, the length, and the width were $10 \mu \mathrm{m}^{2}, 0.3 \mu \mathrm{m}$ and $0.3 \mu \mathrm{m}$, respectively. Fig. 4 shows the changes in the pore area $A_{r}$ and the degree $k_{1}$ of opening of a stoma during the $\mathrm{O}_{3}$ exposure. The slow increase of both $A_{r}$ and $k_{1}$ began from before the exposure and continued until $10 \mathrm{~min}$ (b) after its start. Thereafter, both began to decrease rapidly and reached a constant level at about $25 \mathrm{~min}$ (e). Fig. 5 shows original digital images overlapped with the pore edge at the time points (a) to (f) in Fig. 4. They confirmed that the pore region had been exactly extracted even when the quality of the original image was poor, thus displaying the accuracy of the results.

In the second half of this study, we examined the responses to $\mathrm{SO}_{2}$ of neighboring stomata in a small leaf region of an intact growing plant. Fig. 6 shows a microphotograph of a small region (about $320 \times 320 \mu \mathrm{m}^{2}$ ) in which six stomata were observed. Fig. 7 shows the changes in the degree $\mathrm{k}_{1}$ of the opening of these stomata during the $2 \mathrm{ppm}(\mathrm{v} / \mathrm{v}) \mathrm{SO}_{2}$ exposure. These stomata showed almost uniform and constant $\mathrm{k}_{1}$ until about $20 \mathrm{~min}$ after the start of the exposure, and then a wide variety of stomatal movements began; the largest value in $k_{1}$ was about twice as large as the smallest value at $45 \mathrm{~min}$ and became about three times as large at $90 \mathrm{~min}$. Water-soaking and wilting began to appear in the subsidiary cells at about $55 \mathrm{~min}$, when $\mathrm{k}_{1}$ was a local maximum value, and then all the stomata began to close. This phenomenon was assumed to be caused by increased water loss from the subsidiary cell due to $\mathrm{SO}_{2}$, which affects the membrane and osmotic pressure, with a difference resulting in the turgor between the guard cell and the subsidiary cell (Heath 1980, Unsworth and Black 1981). However, the explanation of guard cell behavior is not the primary objective of this paper. This phenomenon will be examined more thoroughly in a future study.

Changes in stomatal conductance or stomatal resistance of a small leaf region to air pollutants have been investigated using a porometer and a thermal instrumentation system (Unsworth and Black 1981, Omasa et al. 1981b, c). The latter system could show changes in spatial stomatal 


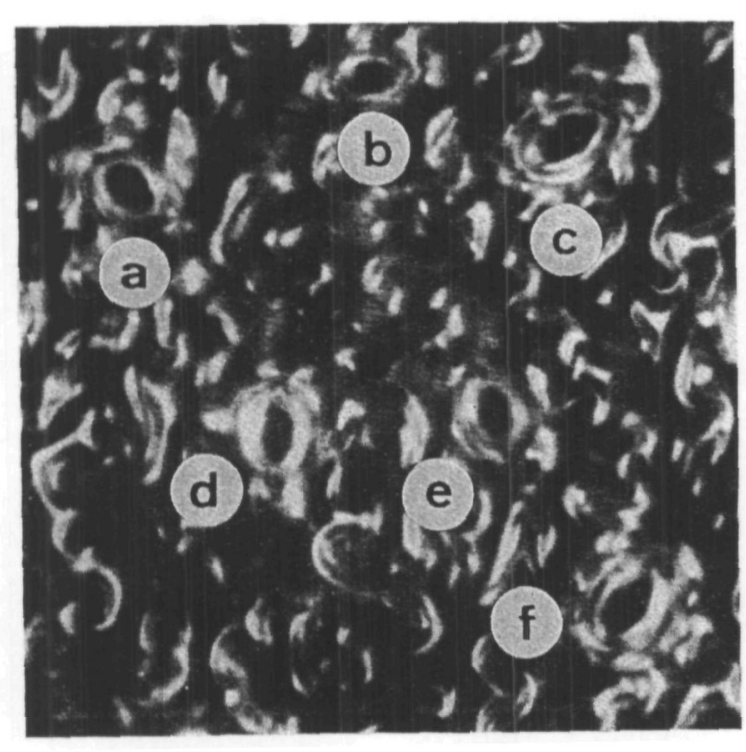

$50 \mu \mathrm{m}$

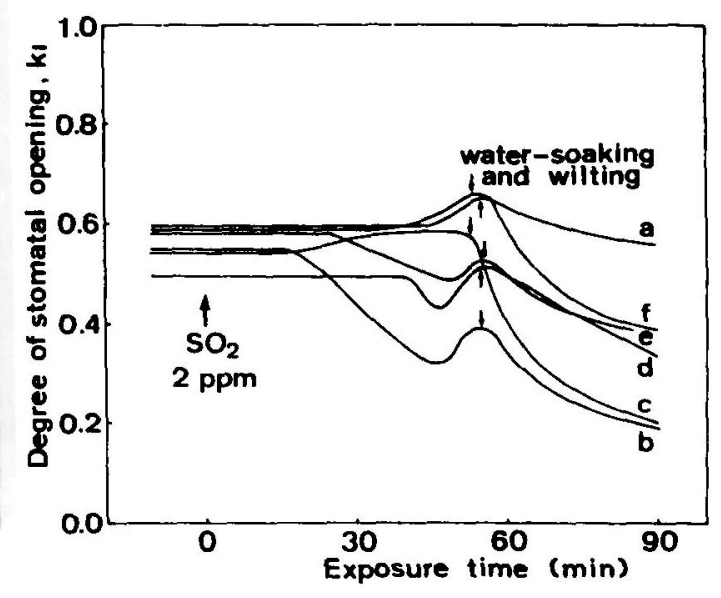

Fig. 7

Fig. 6 Microphotograph of a small region of an intact attached leaf.

Fig. 7 Changes in $k_{1}$ of stomata (a to $f$ ) in Fig. 6 during $\mathrm{SO}_{2}$ exposure. Small arrows ( $\uparrow$ or $\downarrow$ ) show when watersoaking and wilting began to appear.

resistances over an attached leaf and differences have been noticed in the change of the resistance at each leaf site (Omasa et al. 1981b, c). Also, transpiration, which is an indicator of stomatal movements, of a whole plant and one leaf to air pollutants is known to vary with the species, age, growing environment, air pollutant concentration, and other factors (Kondo and Sugahara 1978, Omasa and Abo 1978, Omasa et al. 1979, Furukawa et al. 1979, Unsworth and Black 1981). However, since stomatal resistance and transpiration indicate the average movement of many stomata, they cannot give the responses of each stoma to air pollutants.

In the present study, we showed for the first time the wide variety of responses to $\mathrm{SO}_{2}$ of neighboring stomata of an attached leaf. Our findings suggest that the stomatal responses of intact growing plants to air pollutants should be examined not only by studying the average movement of many stomata but also by examining the movement of each stoma and by investigating the interrelationship among movements of neighboring stomata in order to clarify the mechanism of stomatal responses to air pollutants. Our remote control microscope system (Omasa et al. 1983b), developed to study individual stoma, can be used with the new image processing technique described in this paper to precisely evaluate the degree of stomatal opening and the pore area. Even with images of poor quality, this technique is very effective.

\section{References}

Aiga, I., K. Omasa and S. Matsumoto (1982) Phytotron of the National Institute for Environmental Studies and its energy supply system. J. Soc. Heat. Air-Condi. Sani. Eng. Jap. 56: 741-751.

Castleman, K. R. (1979) Digital Image Processing. p. 429. Prentice-Hall, New Jersey.

Furukawa, A., O. Isoda, H. Iwaki and T. Totsuka (1979) Interspecific differences in responses of transpiration to $\mathrm{SO}_{2}$. Environ. Control in Biol. 17: 153-159. 
Hashimoto, Y. and N. Niwa (1978) Image processing of the information on leaves. Proc. Joint Conf. Image Technol. Jap. 9:51-54.

Hashimoto, Y., T. Morimoto and S. Funada (1983) Image processing of plant information in the relation between leaf temperature and stomatal aperture. In Technological and Methodological Advances in Measurement, Vol. 3. Edited by G. Striker, K. Havrilla, J. Solt and T. Kemeny. pp. 313-320. North Holland Publishing Co., Amsterdam.

Heath, R. L. (1980) Initial events in injury to plants by air pollutants. Annu. Rev. Plant Physiol. 31: 395-431. Hounsfield, G. N. (1973) Computerized transverse axial scanning (Tomography). Brit. J. Radio. 46: 1016-1022. Kondo, N. and K. Sugahara (1978) Changes in transpiration rate of $\mathrm{SO}_{2}$-resistant and -sensitive plants with $\mathrm{SO}_{2}$ fumigation and the participation of abscisic acid. Plant $\&$ Cell Physiol. 19: 365-373.

Mineyuki, Y., M. Takagi and M. Furuya (1984) Changes in organelle movement in the nuclear region during the cell cycle of Adiantum protonema. Plant \& Cell Physiol. 25: 297-308.

Mineyuki, Y., M. Yamada, M. Takagi, M. Wada and M. Furuya (1983) A digital image processing technique for the analysis of particle movements: Its application to organelle movements during mitosis in Adiantum protonemata. Plant \& Cell Physiol. 24: 225-234.

Omasa, K. and I. Aiga (1985) Image instrumentation for evaluating the effects of environmental pollution on plants. In Encyclopedia of Systems and Control. Edited by M. Singh. Pergamon Press, Oxford. (in press).

Omasa, K., I. Aiga and Y. Hashimoto (1983a) Image instrumentation for evaluating the effects of air pollutants on plants. In Technological and Methodological Advances in Measurement, Vol. 3. Edited by G. Striker, K. Havrilla, J. Solt and T. Kemeny. pp. 303-312. North Holland Publishing Co., Amsterdam.

Omasa, K. and F. Abo (1978) Studies of air pollutant sorption by plants (I) Relation between local $\mathrm{SO}_{2}$ sorption and acute visible leaf injury. J. Agric. Meteorol. 34: 51-58.

Omasa, K., F. Abo, I. Aiga and Y. Hashimoto (1981a) Image instrumentation of plants exposed to air pollutantsQuantification of physiological information included in thermal infrared images. Trans. Soc. Instrum. Control Eng. 17: 657-663.

Omasa, K., F. Abo, T. Natori and T. Totsuka (1979) Studies of air pollutant sorption by plants (II) Sorption under fumigation with $\mathrm{NO}_{2}, \mathrm{O}_{3}$ or $\mathrm{NO}_{2}+\mathrm{O}_{3}$. J. Agric. Meteorol. 35: 77-83.

Omasa, K., Y. Hashimoto and I. Aiga (1981b) A quantitative analysis of the relationships between $\mathrm{SO}_{2}$ or $\mathrm{NO}_{2}$ sorption and their acute effects on plant leaves using image instrumentation. Environ. Control in Biol. 19: 59-67.

Omasa, K., Y. Hashimoto and I. Aiga (1981c) A quantitative analysis of the relationships between $\mathrm{O}_{3}$ sorption and its acute effects on plant leaves using image instrumentation. Environ. Control in Biol. 19: 85-92.

Omasa, K., Y. Hashimoto and I. Aiga (1983b) Observation of stomatal movements of intact plants using an image instrumentation system with a light microscope. Plant $\mathbb{E}$ Cell Physiol. 24: 281-288.

Onoe, M., J. W. Tsao, H. Yamada, H. Nakamura, J. Kogure, H. Kawamura and M. Yoshimatsu (1983) Computed tomography for measuring annual rings of a live tree. Proc. IEEE. 71: 907-908.

Onoe, M., K. Preston Jr. and A. Rosenfeld (ed.) (1981) Real-Time/Parallel Computing Inage Analysis. Plenum Press, New York.

Rosenfeld, A. and A. C. Kak (1976) Digital Picture Processing. p. 457. Academic press, New York.

Telewski, F. W., A. H. Wakefield and M.J. Jaffe (1983) Computer-assisted image analysis of tissues of Ethreltreated Pinus taeda seedlings. Plant Physiol. 72: 177-181.

Unsworth, M. H. and V.J. Black (1981) Stomatal responses to pollutants. In Stomatal Physiology. Edited by P. G. Jarvis and T. A. Mansfield. pp. 187-203. Cambridge University Press, Cambridge.

(Received June 4, 1984; Accepted August 23, 1984) 